\title{
Promoting speaking proficiency and willingness to communicate in Turkish young learners of English through asynchronous computer-mediated practice
}

\author{
Louisa Buckingham ${ }^{\text {a, }}$, Rosie Stott Alpaslan ${ }^{\text {b }}$ \\ ${ }^{a}$ University of Auckland, New Zealand \\ ${ }^{\mathrm{b}}$ Bilkent University, Turkey
}

\section{A R T I C L E I N F O}

\section{Article history:}

Received 15 November 2015

Received in revised form 29 December 2016

Accepted 30 December 2016

Available online 5 January 2017

\section{Keywords:}

Young learners

Primary school

Turkey

Willingness to communicate

English language

Speaking practice

Speaking assessment

Educational technology

Audio-visual materials

\begin{abstract}
A B S T R A C T
This study investigated whether the provision of out-of-class speaking practice to young learners of English could contribute to improving speaking proficiency grades, and have a positive impact on children's willingness to communicate. Two intact classes of Grade 3 Turkish learners participated. Recorded communicative exercises provided asynchronous speaking practice homework with the classroom teacher as the children's interlocutor, while the control group received traditional paper-based exercises. The content of materials used in both groups was based on the class syllabus.

A comparison of the speaking test scores of the control and experimental groups revealed that, over a four-month period, the use of the interactive recordings contributed to a significant improvement in the children's assessed oral performance. The implementation was particularly successful in raising the speaking test scores of children who had initially received lower scores. A subsequent ANOVA analysis revealed that the experimental group demonstrated an improvement in their ability to respond confidently with minimal pauses and hesitations, although the length of responses did not change significantly. The integration of such computer-mediated activities for homework speaking practice is potentially particularly useful in contexts where parents lack sufficient English skills to support children with their English-language homework tasks.
\end{abstract}

() 2016 Elsevier Ltd. All rights reserved.

\section{Introduction}

The provision of opportunities to communicate in the classroom constitutes one of the central tenets of communicative language teaching (CLT) and is considered a core principle of contemporary approaches to instructed language learning (Ellis, 2014). Despite opportunities for meaningful oral practice in teaching materials, most teachers have experienced their careful planning come to little fruition with students appearing unwilling to engage in target language communication within the classroom context. While reasons underlying classroom target language avoidance are various, feelings of anxiety and inadequacy appear to be contributory factors (Gregersen \& Horwitz, 2002; Levine, 2003; Tatar, 2005). Previous work also suggests that learners may consider using a foreign language with a person whose L1 they share to be unnatural (Çetinkaya, 2005; MacIntyre, Burnes, \& Jessome, 2011). Alternatively, the time assigned to in-class communicative activities may

\footnotetext{
* Corresponding author.

E-mail addresses: bucklj@gmail.com (L. Buckingham), rosie@bilkent.edu.tr (R.S. Alpaslan).
} 
ultimately not be commensurate with the importance oral communication in the CLT classroom. Class size and the pressure to fulfil curriculum requirements and ensure adequate exam preparation often conspire against the inclusion of more communicative practice (Ho, 2003; Sun, 2012; TEPAV, 2013; Yashima, Zenuk-Nishide, \& Shimizu, 2004).

Evidence suggests that out-of-class language learning experiences may, to varying degrees, compensate for these limitations in the case of motivated learners. Indeed, learners who attain higher achievement levels appear to capitalize on outof-class language learning opportunities (Inozu, Sahinkarakas, \& Yumru, 2010; Lai, Zhu, \& Gong, 2015; Sundqvist, 2011). The characteristics of out-of-class learning vary considerably depending on such variables as location, level of formality, pedagogical approach and locus of control (Benson, 2011). While some out-of-class learning may be self-directed and prioritise entertainment value or non-language outcomes, out-of-class learning may also be linked to coursework and have a formal instructional element.

This study investigates an out-of-class learning opportunity in a self-managed, private, low-anxiety environment (the students' home), where the locus of control is shared between the learner, the parent(s) and the teacher. It reflects a semiformal learning context in that the material is linked to the curriculum and is intended to facilitate the practice of language items from the syllabus. Designed to supplement classroom instruction, the approach represents a form of blended learning.

Traditional paper-based homework materials typically reinforce writing, reading and listening skills but do not enable students speaking practice beyond the classroom. This study employs recorded spoken texts as a learning resource which enables an extension of the customary preserve for instructed speaking practice from the classroom to alternative settings (Ibarz \& Webb, 2007; Webb, 2006), including the home. Recordings provide durable evidence of a learner's speaking ability and pronunciation, which can be used to track the development of oral skills. As a collateral benefit, they also provide additional listening practice.

Whilst this form of speaking exercise is not synchronous and thus does not reproduce the conditions of real-time communication, asynchronous communication is a feature of authentic communication in the form of telephone or social media voice messages.

Comparisons of the pedagogical benefit of synchronous and asynchronous communication are scant. In Satar and Özdener's (2008) study, lower level learners appeared to benefit more from the time delay inherent in (written) textchatting, as opposed to synchronous oral chatting using a computer-mediated communication (CMC) application, owing to the opportunities for rehearsal and planning inherent in this medium. Synchronous computer-mediated speaking tasks are likely better suited to learners of higher proficiency levels due to the higher cognitive load involved in real-time communication. In the case of young learners, asynchronous speaking tasks performed within the home afford children exposure to the language and a motive to use it within their home environment. This form of homework also provides the possibility for parental support (or involvement) with homework in homes where parents have little or no English, as the recordings (rather than family members) provide spoken models of target language.

This study examines the use of technology to support the development of English speaking skills of Grade 3 children at a private primary school in Turkey through asynchronous audio-visual speaking activities (A/Vs). It measures oral proficiency development by comparing learners' speaking assessment grades and traces changes in children's willingness to communicate (WTC) during the intervention period. Previous studies on WTC have tended to focus on teenage or adult learners and, to our knowledge, no studies have previously examined young children's WTC in an L2. Furthermore, as noted in Lin (2014), young learners have been largely neglected in research on computer-mediated foreign language acquisition.

\section{Background}

\subsection{Willingness to communicate}

Derived from the notion of 'unwillingness to communicate' and originally examined from the perspective of communication in the L1 (Burgoon, 1976), the application of the WTC concept to L2 communication is attributed to the work of MacIntyre and associates, who viewed WTC as the "readiness to enter into discourse at a particular time with a specific person or persons, using a L2" (MacIntyre, Clément, Dörnyei, \& Noels, 1998, p.547). The authors argue that a broader range of variables affect one's readiness to communicate in an L2 than in an L1, some of which (such as socio-political factors colouring intergroup perceptions) are immaterial to L1 communication.

Conceptualized as a series of six interrelated layers, the WTC construct developed by MacIntyre et al. (1998) viewed an individual's propensity to enter into communication as a state sensitive to interpersonal, psychological and contextual factors.

The apex of the pyramid (see Fig. 1) constitutes the actual communicative behaviour in the L2. Layer 2 embodies an individual's behavioural intention to communicate, embodied as WTC. This intention is reliant on variables in the preceding layer, which according to MacIntyre et al. (1998, p.54), constitute "the most immediate determinants of WTC", namely 'the desire to communicate with a specific person' and 'state communicative self-confidence'. Positive affiliation with the interlocutor (e.g., through familiarity, perceptions of status or social attractiveness) is considered an important motive in predicting WTC in the target language, together with the individual's perceived competence to communicate in specific situations, and low anxiety, (MacIntyre et al., 2011).

Layer 4 comprises motivational variables which, broadly speaking, represent the propensity to communicate (either as an individual or as a group member) with others, and an individual's overall self-confidence in using the L2. The base layers of the pyramid, layers 5 and 6 , are viewed as more stable variables, which are more distant from the specific communicative 


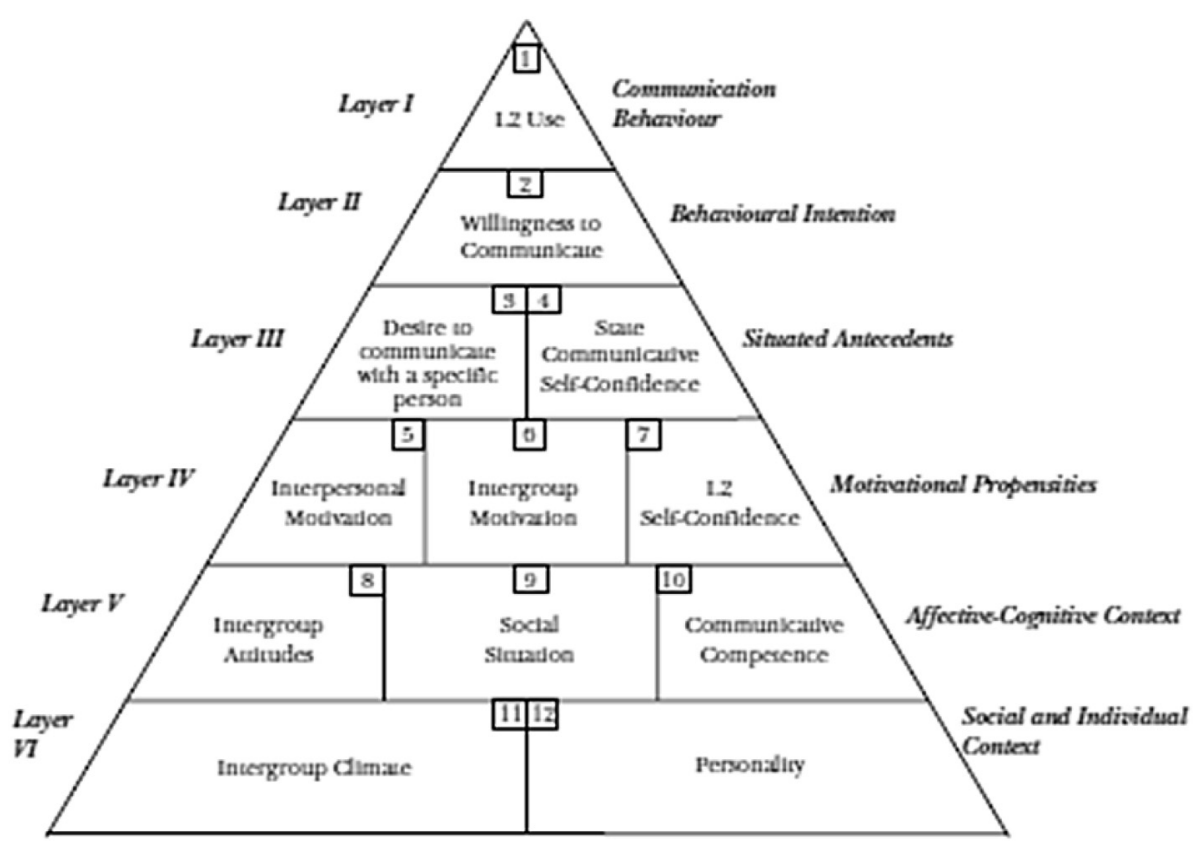

Fig. 1. The pyramidal model of WTC (from Macintyre et al., 1998, p.547).

situation or context. These relate to intergroup perceptions of the L2 community and the speaker's personality and perceptions of his/her communicative competence.

According to the WTC model, a positive disposition towards using the target language is likely to result in the learner responding to opportunities to use the target language. Experience communicating in the target language, in turn, is likely both to benefit the development of communicative competence and contribute to this communicative disposition in future. Classroom teaching should thus endeavour to provide the greatest number of facilitating factors possible within the constraints of the classroom (Gregersen \& MacIntyre, 2014; Kang, 2005).

Most prior studies of L2 WTC have focused on classroom contexts (e.g., Cao, 2011; Cao \& Philp, 2006; Kang, 2005). In this learning environment, variables such as the type of interactional grouping and familiarity with interlocutors and tasks have been shown to impact upon WTC (Cao and Philp, 2006) and that levels of WTC fluctuate both during a lesson and from one lesson to the next (Cao, 2006; Cao, 2014; Kang, 2005). While some are based on self-report data or employ only one data collection instrument (e.g.,MacIntyre et al., 2002; Tok, 2009; Yashima et al., 2004), Cao (2014) and Kang (2005) employed a variety of data collection measures implemented over an extended time period: classroom observations, interviews and journal entries. This emphasis on reflection facilitated insights into the individual learner dimension of WTC and has contributed to framing WTC as a situationally-sensitive construct. Tok (2009) and Çetinkaya (2005) investigated L2 WTC with respect to tertiary-level learners of English in Turkey. Due to the reliance on a self-report data, however, the studies was unable to provide evidence factors which may contribute to the fluctuating nature of WTC.

This study diverges from previous work in three important ways: it examines L2 WTC in an out-of-class context; participants are primary school children; and thirdly, it involves asynchronous CMC.

\subsection{Computer-mediated out-of-class speaking practice}

Previous studies on the development of foreign language oral proficiency through asynchronous computer-mediated communication have employed voice blogs or podcasts as a medium for out-of-class speaking practice. This involves students creating and posting voice recordings to supplement the limited opportunities for oral practice in the classroom.

Sun (2012) and Hsu (2016) investigated the development of complexity, accuracy and fluency among university-level EFL students. Neither study resulted in significant overall gains in oral skills, although in Hsu, some improvement in complexity of student oral production was noted. Both Sun and Hsu note that the informal, personal nature of the blogging genre may have influenced the lack of improvement. In both studies, students received no linguistic feedback and were not encouraged to monitor their output for accuracy. Further, in Sun, students were not required to submit voice recordings intermittently over a stipulated period, and some participants completed the required tasks within a short time span towards the end of the semester.

Ducate and Lomicka (2009) investigated whether tasks involving scripted and extemporaneous recordings (or podcasts) undertaken at regular intervals throughout the semester had positive effects on pronunciation among students of German 
and French. While students in this study received corrective feedback on some recordings, a significant improvement in pronunciation ratings was not noted between the beginning and end or (in most cases) between the intervals during the semester, however. The authors note, however, that the lack of improvement may have also been due to the ceiling effect, as students had already received relatively high ratings for their pronunciation prior to participating in the study.

Although these studies concluded that gains in oral proficiency may require a longer time period than one semester, the weaknesses in the study design invite reconsideration of computer-mediated out-of-class speaking practice. Due to the absence of a control group in all three aforementioned studies, it is impossible to know whether any gains noted were are the result of learning over this time period. Sun (2012) and Ducate and Lomicka (2009) note that increased workloads from other courses late in the semester may have negatively impacted on the time and energy students invested in their voice recordings late in the semester; as a result, it is important to measure students' progress at regular intervals rather than solely comparing assessments at the beginning and end of semester, as seen in Sun (2012).

The recording tasks of these studies required monologue-like speech due to the absence of a speaking prompt from a specific listener. Speaker-listener pairings, usually involving peers, were arranged after the voice task was completed. While students did receive some linguistic feedback in Ducate and Lomicka (2009), this did not specifically come from their course instructor but rather an assistant participating in the study. Such task conditions may be appropriate for university-level language learners who have developed a range of language learning strategies, and who are accustomed to interacting with peers in an online environment. For young learners, however, it was important to replicate the classroom environment and to maintain the classroom teacher as the children's (out-of-class) interlocutor. These factors, involving perceptions of security, familiarity with interlocutors and the responsibility to perform a particular role have been identified as important situational variables impacting an individual's WTC (Cao, 2014; Kang, 2005).

Differences (and certain weaknesses) in the experimental design mean that results from the aforementioned studies on the use of CMC for out-of-class asynchronous speaking practice may be viewed as inconclusive. To the best of our knowledge, no such studies have been undertaken with children.

\subsection{English language instruction in Turkey}

English is the first foreign language studied in Turkey and was designated a compulsory foreign language from Grade 4 in 1997 (Kırkgöz, 2007) and a subsequent education reform in 2013 lowered this to Grade 2 (Milli Eğitim Bakanliği. 2013; Çelik \& Kasapoğlu, 2014). On account of the gradual implementation of this reform, in most state schools English was still introduced in Grade 4 at the time of this study. ${ }^{1}$

The curriculum reform of 1997 sought to introduce a more communicative approach to language teaching, particularly in primary schools. Weaknesses in the implementation of the reform included inadequate class-time to meet curriculum goals and large classes and, in many instances, more traditional teaching methods continued (Uztosun, 2013). The curriculum has undergone subsequent revisions, which led to the introduction of age-appropriate, language-rich activities, and recommendations by the Turkish Ministry of Education that performance-based modes of assessment and portfolios documenting learners' progress be introduced, particularly for younger learners. (Kırkgöz, 2007; Milli Eğitim Bakanlı̆̆1, 2012; 2013).

The most recent curriculum guidelines for primary school stipulate that the focus for young learners (in particular Grades 2-4) should be on oral communication (speaking and listening), with little focus on literacy skills. Accordingly, curriculum content is organised around communicative functions, which for Grade 3 include: describing actions, expressing preferences, describing plans, accepting and refusing, etc. (Milli Eğitim Bakanlığı, 2013).

\subsubsection{The use of technology in Turkish schools}

The integration of technology into the classroom and into the language teaching curriculum offers opportunities to mitigate the limitations of class size and contact time. Until recently, however, scant use was made of technology in educational contexts Turkey (Kızıldağ, 2009). In its 2006 report, Turkey's State Planning Organization (SPO) noted that Internet penetration rates in Turkey were low and expressed concern with respect to the digital divide. However, results from a more recent nationwide state survey on the use of computers and the Internet, show an increase in the access and use of this technology from around 20-30\% of the population in 2007, to around 50\% in 2013 (Turkish Statistical Institute, 2013). Nevertheless, while these figures rise to almost $60 \%$ in urban centres, they fall to just under $30 \%$ in rural locations.

In a bid to support economic and social development and reduce the digital divide, the Turkish government sponsored one of the world's largest educational technology projects, the Fatih Project, to the sum of around three billion Turkish lira (Milli Eğitim Bakanlığı, 2012). With the objective that all school students should graduate with at least basic ICT competence (SPO, 2006: 23), the Fatih Project began equipping schools across Turkey with interactive whiteboards and laptops, and from the 2010-2011 school year assigned a tablet to each school student (ERI, 2013). According to media reporting, around 1.5 million teachers and students had received tablets by early 2016 (Daily Sabah, 2016).

\footnotetext{
${ }^{1}$ The prominence accorded to English at primary school continues through secondary school. Many of the English-medium schools rank among the most prestigious secondary schools in the country. English proficiency facilitates admittance to Turkey's top universities, most of which are partially or wholly English medium. Students without the required level are channelled into a year-long university preparatory programme (Selvi, 2011).
} 
The relatively high cost and poor penetration of Internet infrastructure (SPO, 2006) are a potential obstacle to the project's impact. In recognition of this, the government recently promised free Internet provision to low income families (Hürriyet, 2015). Despite being originally criticised as a project which prioritised hardware over facilitating contextual factors such as user training and improving out-of-class Internet access (ERI, 2013; TEPAV, 2013), it appears that these may receive greater attention in future.

\section{Methods}

\subsection{The study}

This quasi-experimental study with two intact Grade 3 classes (an experimental and control group) aimed to ascertain whether the completion of A/Vs as homework would improve the children's speaking assessment scores over one semester (four months) in the 2013-2014 academic year. The experimental group was required to complete the normal homework orally, while the control group completed the same homework tasks in the traditional written form. Progress was evaluated by comparing the speaking test scores of the experimental and the control group.

The second objective of this study was to investigate whether any change can be identified in the children's WTC over the implementation period, as evidenced by their recorded responses. It was anticipated that factors such as the low anxiety learning context, the familiarity of the speaker in the recordings and topics in the activities would be conducive to the improvement in children's WTC.

Ethical approval for this study was obtained from the Turkish Ministry of Education, and written informed consent was received from the children's parents.

The specific questions addressed by this study are as follows:

1 Does the completion of audio-visual speaking activities have a positive impact on children's speaking assessment scores?

2 What development can be observed in children's WTC over the duration of the intervention?

\subsection{Context and participants}

The study was undertaken at a private, Turkish-medium primary school located on the campus of one of Turkey's prestigious English-medium universities in the capital. The standard of English tuition students receive at school is considered high within the Turkish context. The majority of students and teachers are Turkish nationals. The school implements the International Baccalaureate Organization's (IBO) 'Primary Years Programme' (PYP) ${ }^{2}$ and follows a curriculum based on a program of inquiry, the development of concepts, skills and attitudes. The primary school has four Grade 3 classes, each with around 20 students. Students have eleven 40-min English lessons a week.

Students at this level are assessed formatively through semi-formal weekly speaking assessments, and the achievement level is noted on a report card provided to parents at six-week intervals. The descriptors on the rubric used to assess speaking (see Table 1) are converted into the following statements on the report card: 'needs more work' (Level D and Level 1), 'satisfactory' (Level 2) and 'successful' (Levels 3 and 4). In reflection of the aforementioned importance accorded to knowledge of grammar and vocabulary, speaking assessments undertaken with the learners at this level place importance on learners' use of the grammar and vocabulary taught in the school syllabus.

This study takes place within a middle-class socioeconomic milieu. The parents of children attending this school tend to be educated professionals. They choose to enrol their children in an International Baccalaureate (IB) -affiliated institution with a strong English language programme staffed by qualified native speaker English teachers, and can afford private school fees. The successful implementation of this study required parents' collaboration. In light of the urban setting and the relatively privileged socioeconomic status of families in this study (compared to the broader populace), it would be reasonable to suppose a positive posture from parents with regard to providing an environment supportive of homework aimed at improving English language speaking skills through technology. ${ }^{3}$

Two classes with 19 and 21 children respectively were randomly chosen $(n=40)$ from the three third grade classes at the school. The participants (19 boys and 21 girls aged between eight and nine) all had Turkish parents and spoke exclusively Turkish at home. The second author is the teacher of these classes and is responsible for the grades and speaking assessments. The classes were randomly assigned to either the experimental or control group.

\footnotetext{
${ }^{2}$ Only 19 primary schools in Turkey are authorized to deliver the IBO 'Primary Years Programme' (www.ibo.org).

${ }^{3}$ Previous work has shown that Turkish parents in more advantaged urban socio-economic contexts value the development of self-reliance and autonomy in their children (Kağitçibaşi, 2007), provide more learning materials to their children and report an earlier level of skill development than is the case of mothers in provincial or semi-urban settings (Nacak, Yağmurlu, Durgel, \& van de Vijver, 2011).
} 
Table 1

Descriptors used in Grade 3 speaking assessments. ${ }^{a}$

\begin{tabular}{cl}
\hline Level & Descriptor \\
\hline Level & Student uses more than the required useof target structures and patterns, relatively error free-word order, verb tense, and word endings that \\
4 & mayconfuse meaning and comprehension. \\
Level & Student uses the requiredtarget structures and patterns, relatively error free -word order, verb tenses, and work endings that sometimesconfuse \\
3 & meaning and comprehension. \\
Level & Student uses requiredtarget structures and patterns, with occasional errors in word order, verb tenses, and word endings that sometimesconfuse \\
2 & meaning and comprehension. \\
Level & Student attemptsto use the target structures and patterns, with frequent errorsin word order, verb tense, and word endings that confuse \\
1 & meaning and comprehension. \\
Level & Student cannot recognizeor produce target structures and patterns. \\
D &
\end{tabular}

a Adapted from Herrera, M. and Sol Cruz, C. 2012. Big English 3 Assessment package. Pearson Education.

\subsection{Instruments}

Two sets of speaking assessment scores were used as measures in this study. In addressing the first research question, we employed the in-class speaking assessment scores. These were collected at the beginning and end of the study. To assess children's WTC (research question 2), the assessment scores for children's performance on the asynchronous A/V speaking activities were used. These were collected on four occasions. Over the same period, the control group received the same input in the form of a worksheet.

\subsubsection{Speaking assessments: pre- and post-tests}

A pre-test was conducted to identify whether the two classes were at a comparable level at the beginning of the study. The content of the test focused on the language covered in the syllabus at this level ${ }^{4}$ and did not include new items. Each student was assessed individually in class over two 40-min class periods using the usual oral assessment format children were accustomed to. A post-test was conducted to measure the degree of improvement in each learner's English speaking skills at the end of the implementation period. The content of the post-test was a mixture of the grammar and vocabulary covered in the four topics during this period.

The school uses a standardized framework for oral assessments to ensure the same procedure was followed in all classes. ${ }^{5}$ This procedure was used in the pre-tests and the post-tests of this study. The framework comprised 11 questions and was broken into three sections (warm-up short-answer questions, description of a picture, and questions about the learner). The picture used was taken from the coursebook's assessment materials and the language elicited corresponded to the course syllabus content. The framework includes rephrased questions as a backup in case a learner fail to respond. The grading rubric appears in Table 1.

Children's performance during the pre- and post-tests was recorded and assessed by the second author and reassessed by a second teacher of this level to strengthen assessment reliability. In the case of divergent grades, the teachers listened again to the respective recordings and discussed their proposed grade with reference to the rubric to reach an agreed grade. Discrepancies in the grade assigned occurred in no more than three instances for each test. In no case did each discrepancy constitute more than one point on the rubric scale.

\subsubsection{Assessment of willingness to communicate}

To assess children's WTC in their recorded responses in the A/V PowerPoint (PPT) materials, we used a rubric adapted from the Heuristic Model of Variables Influencing Willingness to Communicate (MacIntyre et al., 1998). Two criteria were used to evaluate the level of WTC: 'extension' and 'response'.

The first criterion, 'extension', corresponds to layer three of the WTC pyramid: the speaker's self-confidence in his/her ability to communicate in the given situation with a specific interlocutor (in this case the teacher). For children to progress from 'no response' to answering the questions, learners need sufficient self-confidence in their ability to respond appropriately. Anxiety or low confidence in their English-language ability is likely to result in shorter answers, no response, or a response wholly or predominantly in Turkish. The second criterion, 'response', corresponded to layer two of the WTC pyramid and is defined as the readiness to engage in L2 discourse at a particular time with a specific person (MacIntyre et al., 1998). In a classroom environment, this disposition may be demonstrated by an oral response or the physical action of raising one's hand. In the context of the A/Vs, the attempt to respond was measured in terms of the extent of hesitations and pauses during the learner's response. Both variables are situated within the apex of the WTC pyramid and represent the two "fluctuating situated antecedents" of an individual's intention to communicate (Gregersen \& MacIntyre, 2014: 215).

\footnotetext{
4 The target structures encompassed present continuous, I like + noun, present simple, and prepositions of place.

5 Short, weekly formative speaking assessments of all children take place throughout the year in the classroom during class time. Despite following a standardized procedure, a relaxed atmosphere is created through the familiar setting and the informal, conversational format of the assessment.
} 
The assessment of the 'extension' variable proceeded as follows. Answers which provided more than what was expected and furnished additional details were given a score of three. ${ }^{6}$ For example, if the teacher asked 'What is your favourite animal?', the student might respond 'I like lions because they are strong and I like tigers'. If the student answered appropriately using one clause or sentence, a score of two was given, for example, 'I like lions'. A response comprising isolated words such as 'lions' or 'strong' was given a score of one. A score of zero indicated the student failed to respond or responded primarily in Turkish with insufficient English used to be comprehensible. Responses which included some Turkish were not penalized, provided the main content words were in English. ${ }^{7}$

In the case of the 'response' variable, children who spoke freely and appeared not to experience hesitations while speaking received a score of three. A score of two was given to a response with some hesitations or pauses. A score of one was given to responses which had hesitations or pauses which disrupted the perception of smooth communication. A score of zero meant the student did not respond or spoke in Turkish.

To strengthen assessment reliability, two A/V PPTs were randomly selected and graded by a second assessor (a teacher experienced in this level) upon completion of each unit. If the grades differed, the PPTs concerned were re-assessed by the researcher and a second assessor to reach a consensus.

3.3.2.1. Audio-visual speaking activities. Each set of speaking activities, containing video and voice recordings of the teacher, images and text, was created using PPT (an excerpt appears in Appendix 1). The children recorded their answers to the questions posed in the teacher's recordings onto the same PPT slide. The topic of each set corresponded to each of the four units of the coursebook covered during this period and the titles matched those of each unit. These were: Awesome Animals, Sunny Days, My Five Senses and Fabulous Food. Each A/V PPT contained between five and seven short exercises, accompanied by brief explanations and examples, for the child to complete orally (see Appendix 2 for a description of Awesome Animals).

A trial A/V PPT was shown to ten experienced teachers of young learners in the English section at the school. These teachers were familiar with the Grade 3 syllabus requirements, the coursebook and the assessments used at this level. These teachers completed a feedback form about the layout, length, progression of activities and presentation of information on the slides. In response to the teachers' feedback, the difficulty level of some tasks and the amount of spoken input in the teacher's recordings were adjusted, and some visual features were re-designed.

The slides progressed in level of difficulty in that earlier exercises were more controlled (or more form-focused), and freer (or more meaning-focused) exercises occurred later. The more controlled tasks provided scaffolding for the freer tasks in that they introduced vocabulary or phrases children could recycle in the freer exercises. Each $\mathrm{A} / \mathrm{V}$ followed a similar structure and was approximately the same length. This meant children quickly became accustomed to the type of tasks required of them and the logistics involved in recording responses.

The same opportunities for parental supervision and task rehearsal or repetition were retained in the A/Vs. Children could seek help from their parents or the textbook, and they could rehearse and re-record an exercise. The latter information was included on the instruction sheet for parents. The reasons for this were twofold. Firstly, any homework assigned by the teacher is likely to be completed by children of this age with some degree of parental supervision; secondly, children have the option of erasing and re-doing traditional paper-based homework tasks.

3.3.2.2. Worksheet homework. During the same period that the experimental group received the $\mathrm{A} / \mathrm{Vs}$, the control group undertook homework in the form of a paper-version of the audio-visual learning activities. This worksheet replicated the form of homework that the children usually receive. The activities were modelled on those in the coursebook and they contained the same topics and questions as the $\mathrm{A} / \mathrm{V}$ homework, but elicited written rather than spoken responses. Such responses required a limited amount of writing (words, a short one clause sentence, e.g., I like lions), in addition to underlining words or drawing a line to connect words and images. The completed homework was collected by the teacher and simple written feedback was given to each student.

\subsection{Procedure}

Over one semester, the experimental group was given monthly homework in the form of a set of A/Vs using PPT. During this period, the control group was given worksheet homework. Each PPT or worksheet corresponded to the topic and language of one unit of the coursebook. Both groups were given three days to complete the homework. Upon receiving each A/V PPT, the second author graded the learner's oral performance in English according to two WTC variables, using criteria described below. Learners were given brief written feedback ${ }^{8}$ on their overall performance in the recordings on a

\footnotetext{
${ }^{6}$ It is general practice in the English section of this school during oral assessments to encourage children to use full sentences in their responses (where applicable) with as much detail as they can manage.

${ }^{7}$ For instance, Turkish filler words, such as 'yani', commonly used by Turkish speakers of English across all proficiency levels and age groups, were not penalized.

${ }^{8}$ This feedback comprised a supportive global comment, a comment related to the content and an example of a linguistic element that the learner could work on (e.g., 'Good work! I also like lions. Remember to use 'a' - a shark can swim').
} 
standardized feedback sheet that was saved onto a USB stick. The same form of feedback was given to the learners in the control group. This process was repeated for each month.

The PPT application was used as a platform for the A/Vs as the use of Microsoft Office is widespread in Turkey. We anticipated that many parents would be familiar with the basic functions of PPT, even if they had no previous experience with the recording function of this software, and this was verified in an initial questionnaire to parents. Instructing parents on how to use this additional feature was considered to present less of a challenge than introducing parents to an entirely new application.

A USB stick was used to transport the A/Vs between the children's home and school. This method was preferred over the use of a shared cloud storage platform as it was judged that most parents were unfamiliar with cloud storage and, at the time of the study, not all households could be assumed to have sufficient bandwidth to support file sharing.

At the beginning of the study, the experimental group was given a demonstration of how to use PPT, play recordings and record their answers. Despite some familiarity with PPT from their ICT lessons, they had not previously used the recording function. A trial run (not assessed) was held with a model A/V PPT (similar to the ones used in the study) to identify and address any technical or procedural difficulties experienced by the children or their parents. Parents received an illustrated instruction sheet in Turkish on using the PPT recording function. Parents were also informed that the exercises were intended to stimulate their child's speaking skills and that their child could plan his/her response (and repeat the task), but should not read out written responses. ${ }^{9}$

The first research question was addressed by analysing the results of pre- and post-tests by an independent $t$-test. For the second research question, continuous assessment was also undertaken of the children's performance on the A/V PPTs. The grades assigned to each PPT were analysed using a repeated-measures ANOVA. Subsequently, Bonferroni post-hoc tests were undertaken to identify in which months differences in grades occurred. The significance value for all statistical analyses was set at 0.05 . No comparison could be made with the control group for the second question, as these children had competed the traditional paper-based homework.

\section{Results}

\subsection{Speaking assessment scores}

An independent samples $t$-test was conducted to compare the control and experimental groups' speaking assessment scores at the beginning of the study to ensure the two groups were at a comparable level. No significant difference was found in the speaking assessment grades of learners in the experimental group $(\mathrm{M}=2.15, \mathrm{SD}=0.95)$ and the control group $(\mathrm{M}=2.52, \mathrm{SD}=1.20)$ at this stage $(\mathrm{t}(38)=1.05, \mathrm{p}=0.62)$. The two groups thus had a similar level of English proficiency, although the control group had a higher pre-test mean.

To identify whether a significant change occurred in the speaking assessment scores of each group between the beginning and the end of the study, we conducted two paired samples t-tests. With respect to the experimental group, a significant difference was found at the end of the study $(M=3.05, S D=0.62)$ compared to the beginning of the study ( $M=2.15$, $\mathrm{SD}=0.95) ; \mathrm{t}(18)=-5.28, \mathrm{p}=0.00$. A comparison of the speaking assessment scores of the control group at the beginning $(\mathrm{M}=2.52, \mathrm{SD}=1.20)$ and end $(\mathrm{M}=2.47, \mathrm{SD}=0.87)$ of the study showed no significant difference, however, $\mathrm{t}(20)=0.37$, $\mathrm{p}=0.71$.

To identify whether there was any significant difference in the degree of improvement in the post-test grades of the experimental and the control groups, an independent samples $t$-test was performed. A significant difference in the scores was found between the experimental group $(\mathrm{M}=3.05, \mathrm{SD}=0.65)$ and the control group $(\mathrm{M}=2.47, \mathrm{SD}=0.87)$ at the end of the study $(\mathrm{t}(38)=-2.38, \mathrm{p}=0.022)$. These results suggest that the implementation of the A/Vs had a positive impact on learners' speaking skills.

The overall level of learners in the experimental group increased to a greater extent than that of learners in the control group. The weaker learners in the experimental group, assessed to be at level 1 or level 2 of the assessment rubric (see Table 2) at the pre-test stage, shifted to levels 3 and 4 at the post-test stage. No student remained at level 1. This suggests that the additional personalised support at home was particularly beneficial for weaker learners. In comparison, the majority of learners in the control group remained at the same level and almost half were assessed to be at level 1 or 2 in the post-test.

\subsection{WTC scores (extension and response)}

Children's WTC was assessed through two variables (extension and response) and the assessments were undertaken on four occasions. In the case of the scores assigned to extension, a repeated measure ANOVA revealed no significant differences between the months of February and May $(F(3,54)=1.15, \mathrm{p}=0.337)$. This form of activity thus did not lead to children's use of longer responses in place of phrases or isolated words.

\footnotetext{
${ }^{9}$ All communication with parents occurred in Turkish. Parents were encouraged to contact their child's teacher at any stage to clarify any matter related to the study and they received the relevant contact details.
} 
Table 2

Assessed level of learners in pre- and post-tests.

\begin{tabular}{|c|c|c|c|c|c|c|c|}
\hline & & \multicolumn{6}{|c|}{ Level } \\
\hline & & 0 & 1 & 2 & 3 & 4 & Total \\
\hline \multirow[t]{2}{*}{ Experimental Group } & Pre-test & - & 7 & 2 & 10 & - & 19 \\
\hline & Post-test & - & - & 3 & 12 & 4 & 19 \\
\hline \multirow[t]{2}{*}{ ControlGroup } & Pre test & 2 & 2 & 4 & 9 & 4 & 21 \\
\hline & Post-test & - & 3 & 7 & 9 & 2 & 21 \\
\hline
\end{tabular}

With respect to the response scores, significant differences were found between February and May $(\mathrm{F}(3,54)=13.44$, $\mathrm{p}=0.00)$. Bonferroni pair-wise comparisons further revealed significant differences between February and April $(\mathrm{p}=0.005)$, February and May $(\mathrm{p}=0.00)$, March and May $(\mathrm{p}=0.001)$, and April and May $(\mathrm{p}=0.005)$. In these four periods, the learners' response scores showed a significant increase. The post-hoc test also revealed that there were no significant differences in the response scores between the months of February and March $(\mathrm{p}=1.00)$ and the months of March and April $(\mathrm{p}=0.812)$. This month-to-month difference in learners' response scores is displayed in Table 3. When the last month (four) is compared with the other three months separately, a positive improvement of response scores is found. That is, children produced fewer hesitations and pauses in their recorded responses by the end of the implementation period.

The total scores of WTC (i.e., extension and response combined) showed statistically significant differences between February and May and March and May. This overall improvement in these two WTC variables was only visible by the end of the study; statistically significant differences could not be detected month to month. Thus, whilst children's WTC developed over the four-month period, progress was gradual.

\section{Discussion}

The positive improvement in the speaking scores of the experimental group in this study supports findings in Kirkgöz (2011), according to which the use of audio-visual oral practice as homework resulted in improvements in students' language use (pronunciation, vocabulary and accuracy). The improvement in learners' speaking assessment grades appears to be attributable to the provision of this additional out-of-class speaking practice.

Various factors inherent in the activity type may have contributed to this positive outcome. The A/Vs provided opportunities for task rehearsal, the benefits of which on language production have been documented with respect to traditional classroom tasks (Ellis, 2009). Additional features of this medium which likely benefited the learners' performance included audio-visual language cues, the availability of parental support, the presence of the children's teacher as their interlocutor in the home context, and the attempt to simulate to a certain degree the familiar classroom context.

The fact that teacher feedback in this study provided attention to accuracy and fluency, in addition to supportive global feedback, may have contributed to the improvement in the speaking assessment grades. In previous studies by Sun (2012) and Hsu (2016) which used asynchronous speaking blogs to support speaking proficiency, students did not receive feedback. While students perceived an improvement in their speaking skills by the end of the study, the analysis of their oral production did not reveal evidence of improvement. That students did perceive an improvement (in particular, in fluency and the organization of ideas) should, however, be viewed as valuable in its own right, as positive self-perceptions of communicative competence contribute to an individual's WTC. In Ho (2003), learners did not receive feedback on their asynchronous recorded speaking performance and they specifically requested this in their post-study reflections on the tasks.

Progress in learners' WTC appeared to be a gradual phenomenon and significant changes in the WTC variables analysed in this study were only detectable from beginning to end and not on a monthly basis. Improvements occurred in the response criterion (the occurrence of hesitations and pauses). This indicates that by the end of the study learners were able

Table 3

Significance of WTC scores (month to month).

\begin{tabular}{|c|c|c|c|c|c|c|c|c|c|c|c|c|}
\hline \multicolumn{13}{|c|}{ WTC Criteria } \\
\hline \multirow[t]{2}{*}{ Month } & \multicolumn{4}{|l|}{$\mathrm{E}$} & \multicolumn{4}{|l|}{$\mathrm{R}$} & \multicolumn{4}{|c|}{ Combined scores } \\
\hline & 1 & 2 & 3 & 4 & 1 & 2 & 3 & 4 & 1 & 2 & 3 & 4 \\
\hline February & & & & & & & $*$ & $*$ & & & & $*$ \\
\hline March & & & & & & & & * & & & & * \\
\hline April & & & & & $*$ & & & $*$ & & & & \\
\hline May & & & & & $*$ & $*$ & $*$ & & $*$ & $*$ & & \\
\hline
\end{tabular}

Note: Month 1 = February, 2 = March, $3=$ April, $4=$ May.

$\mathrm{E}=$ Extension.

$\mathrm{R}=$ Response.

* = Significant at $\mathrm{p}=<0.05$. 
to answer the questions with fewer pauses and hesitations and were perceived to respond more smoothly and confidently. This variable is important as the reduction in pauses and hesitations contributes to a perception of greater fluency and communicative ease (Gregersen \& MacIntyre, 2014). Of note is the support this type of out-of-class activity appeared to provide to weaker learners. The children in the experimental group whose level was initially assessed as weak improved their speaking scores.

This type of extramural A/V activity appears to support the development of reflection, autonomy and confidence, in that learners have control over how often they listen to, re-record and review the speaking texts. Among university-level learners, the use of CMC for pedagogical purposes appears to have a positive influence on students' perceptions of their degree of learning autonomy and confidence (Sanprasert, 2009).

The encouragement of student reflection and confidence with respect to their learning is an important component of the IB PYP curriculum (as implemented in this school) and these are capacities which are recorded in the IB PYP Learner Profile ${ }^{10}$. According to previous research from the Turkish context, however, attempts to encourage greater learner autonomy through the use of digital technology may conflict with learner expectations of clear direction and structure from the teacher during the learning process (Inozu, 2011). This reinforces the need at lower levels of learner proficiency for CALL learning materials that are clearly linked to the syllabus and delivered with guidance and feedback from the teacher (Ayres, 2002).

Discrepancies in the penetration of digital technology in rural and urban settings (Ergül, Gökalp, \& Cangöz, 2015; Turkish Statistical Institute, 2013) inevitably means that the relatively favourable conditions present in this study for the out-of-class use of digital technology cannot necessarily be assumed in the broader Turkish population. Nevertheless, the uptake of digital technology in disadvantaged social sectors appears to be rising. Recent work on the 'digital transformation' of contemporary Turkey has identified the importance attributed to the ownership and use of digital devices amongst individuals from underprivileged socioeconomic sectors with low educational levels (Ergül et al., 2015). The authors observed that parents resourcefully incorporated digital technology into their lives, when this was perceived as a useful source of information or communication. This suggests that many parents from lower socio-economic sectors may also actively support their children's use of digital technology for out-of-class schoolwork. Also, as the Fatih Project matures, the level of ICT provision available in urban settings is expected to extend to rural areas.

\section{Conclusions and future directions}

This study has investigated whether the use of computer technology to deliver out-of-class speaking practice can contribute to improving young learners' speaking proficiency scores and can positive impact on learners' willingness to communicate. Using an experimental research design with two groups of Grade 3 learners in Turkey, a significant improvement was found in the assessment scores for the experimental group but not for the control group.

In this study, learners' oral performance was evaluated by semi-formal and formal assessments and the structured nature of these events, combined with their assessment purpose may have influenced children's responses. Future studies of this type might also focus on learners' performance in spontaneous, naturalistic communicative events, together with an examination of learner's levels of confidence and anxiety. This would provide a more comprehensive understanding of variations in learners' WTC in different contexts across an extended time period.

Previous research has shown that the integration of educational technology can have a positive impact on learner attitudes and motivation (Abaylı, 2001; Shenton \& Pagett, 2007; Kırkgöz, 2011). Longer term research would be needed to assess whether the novelty factor may contribute to this positive impact of CMC (see, for instance Moss et al., 2007; Sun, 2012).

Finally, the parents in this study were all computer conversant and all (except two) had some degree of English competence. Although all communication with parents was conducted in Turkish, further research is nevertheless needed to ascertain whether adaptations to the activity design would be advisable for households where parents have little or no English ability or experience with computers, that is, in more characteristically representative Turkish contexts (see TEPAV, 2013). If this type of activity can also be successfully implemented in such learning environments, the use of technology for extramural schoolwork can potentially bring the spoken language into the homes of socially underprivileged families where parents have, to date, been unable to assist children with English language homework.

\section{Acknowledgements}

The authors gratefully acknowledge the collaboration of the parents and children in this study.

\section{Appendix 1}

Excerpts from the A/V PPT: Awesome Animals (slides 4 and 5).

\footnotetext{
$\overline{10}$ The learner profile is a description of capacities and responsibilities which the IB programmes seek to develop (http://www.ibo.org/en/benefits/learnerprofile).
} 
Slide 5. Recorded text: "Where do they live? For example: A camel lives in the desert. Look at the pictures and talk about where the animals live".

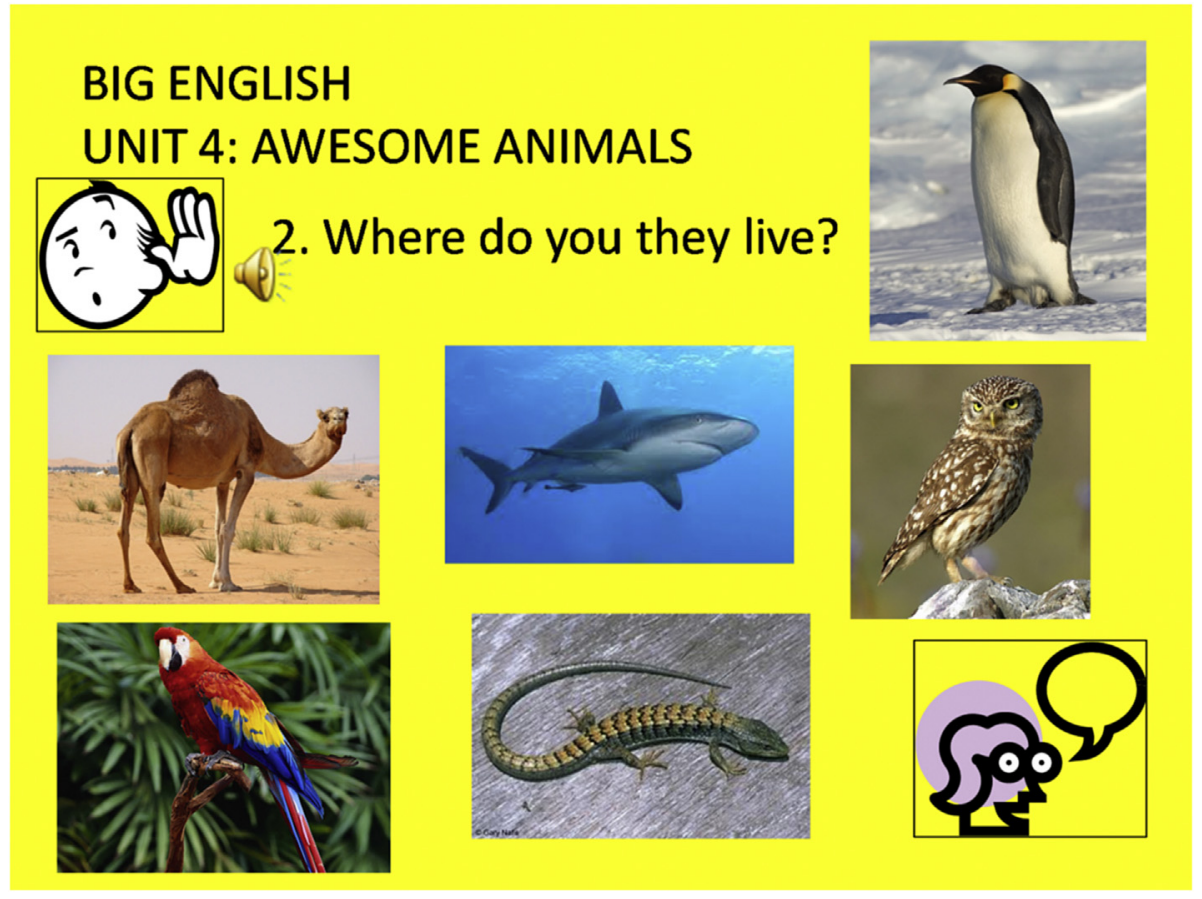

Slide 6. Recorded text: "What can they do? A camel can run fast but it can't fly. Talk about what the animals can and cannot do, use the box to help you".

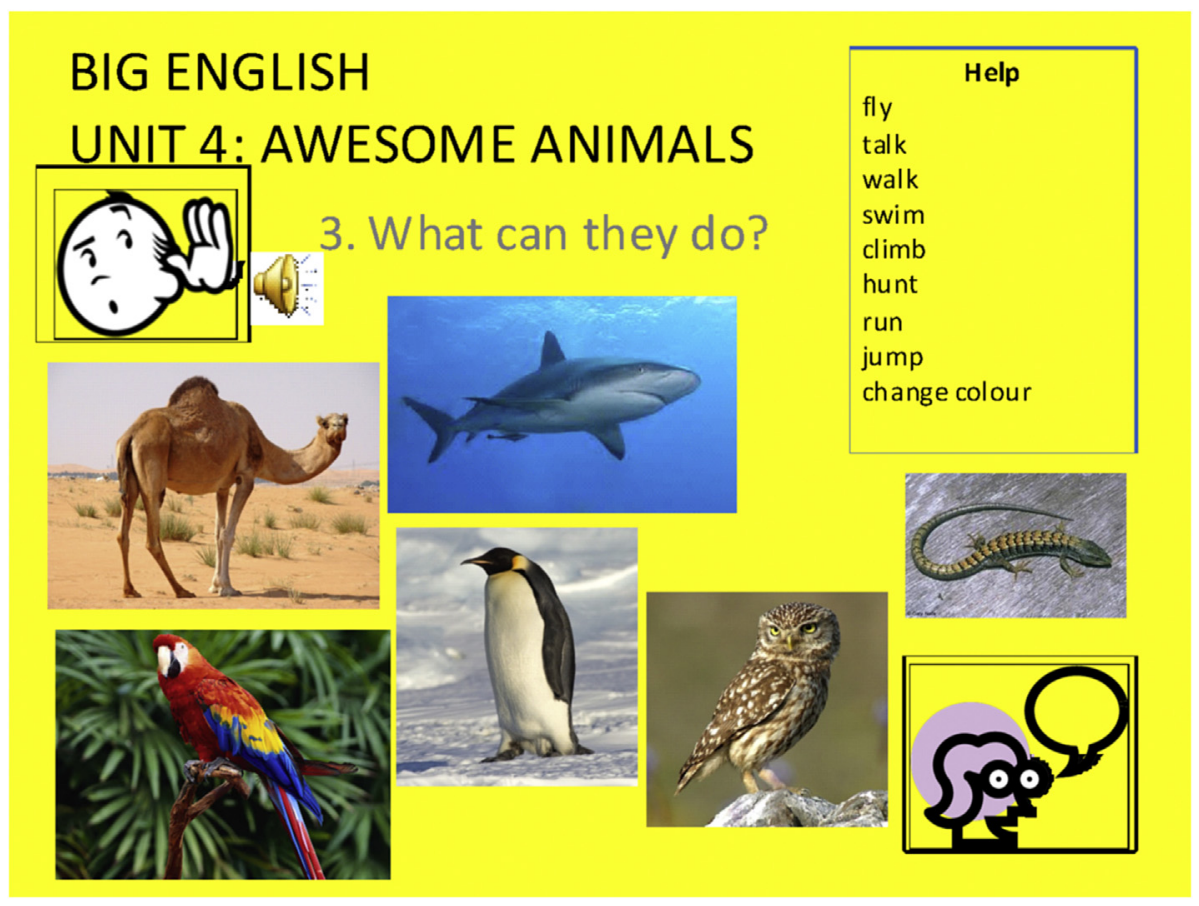




\section{Appendix 2}

Description of A/V PowerPoint content (Awesome Animals)

\begin{tabular}{ll}
\hline Slide No. & Content \\
\hline $\begin{array}{l}\text { Slide } 1 \\
\text { Slide } 2\end{array}$ & $\begin{array}{l}\text { Presented the icons used throughout the PPT to show the students when to speak, listen and record } \\
\text { The topic and several key words for the unit (e.g., elephants, lions, and penguins), accompanied by images of animals. The respective } \\
\text { student's name and a greeting. } \\
\text { A filmed greeting message from the teacher (the second author), who was seated in the classroom with a large picture of the class mascot } \\
\text { visible in the background. } \\
\text { Pictures of animals and recorded instructions from the teacher asking students to name the pictures. The icon to prompt students to record } \\
\text { their answers. }\end{array}$ \\
Slide 5 & $\begin{array}{l}\text { Pictures of the same animals and recorded instructions from the teacher asking students to say where the animals live. A recorded example } \\
\text { with the target structure was provided. The icon to prompt students to record their answers. } \\
\text { Open-ended questions and a help box with verbs. The icon to prompt students to record their answers. } \\
\text { Slide } 7\end{array}$ \\
Slide 8 & $\begin{array}{l}\text { Recorded instructions from the teacher asking students to name their favourite animals and gave reasons for their preferences. } \\
\text { The students were congratulated and reminded students to save their work and hand their USB to the teacher at school. }\end{array}$
\end{tabular}

\section{References}

Abaylı, N. (2001). An investigation of students and teachers attitudes toward the video class. Unpublished Master's thesis. Ankara: Bilkent University.

Ayres, R. (2002). Learner attitudes towards the use of CALL. Computer Assisted Language Learning, 15(3), 241-249.

Benson, P. (2011). Language learning and teaching beyond the Classroom: An introduction to the field. In P. Benson, \& H. Reinders (Eds.), Beyond the language classroom (pp. 7-16). London: Palgrave Macmillan.

Burgoon, J. K. (1976). The unwillingness-to-communicate scale: Development and validation. Communication Monographs, 43, 60-69.

Cao, Y. (2006). Temporal fluctuations in situational willingness to communicate in a second language classroom. New Zealand Studies in Applied Linguistics, $12(2), 1-16$.

Cao, Y. (2011). Investigating situational willingness to communicate within second language classrooms from an ecological perspective. System, 39, $468-479$

Cao, Y. (2014). A sociocognitive perspective on second language classroom willingness to communicate. TESOL Quarterly, 48(4), 789-814.

Cao, Y., \& Philp, J. (2006). Interactional context and willingness to communicate: A comparison of behaviour in whole class, group and dyadic interaction. System, 34, 480-493.

Celik, S., \& Kasapoğlu, H. (2014). Implementing the recent curricular changes to English language instruction in Turkey: Opinions and concerns of elementary school administrators. South African Journal of Education, 34(2), 1-14.

Çetinkaya, Y. B. (2005). Turkish college students' willingness to communicate in english as a foreign language (Doctoral dissertation). Retrieved from ProQuest. (3197824).

Daily Sabah. (2016). FATiH education project hailed in Europe. Retrieved from: http://www.dailysabah.com/education/2016/03/16/fatih-education-projecthailed-in-europe.

Ducate, L., \& Lomicka, L. (2009). Podcasting: An effective tool for honing language students' pronunciation? Language Learning \& Technology, 13(3), 66-86.

Education Reform Initiative, (ERI). (2013). Turkey's Fatih project: A plan to conquer the digital divide or a technological leap of faith? Istanbul: Sabanc1 University.

Ellis, R. (2009). The differential effects of three types of task planning on the fluency, complexity, and accuracy in L2 oral production. Applied Linguistics, 30 , $474-509$.

Ellis, R. (2014). Principles of instructed second language learning. In M. Celce-Murcia, D. M. Brinton, \& M. A. Snow (Eds.), Teaching English as a second or foreign language (pp. 31-45). Boston: Heinle.

Ergül, H., Gökalp, E., \& Cangöz, I. (2015). New media, everyday life, and the poor: An ethnographic inquiry. In D. Akdenizli (Ed.), Digital transformations in Turkey (pp. 21-45). London: Lexington Books.

Gregersen, T., \& Horwitz, E. K. (2002). Language learning and perfectionism: Anxious and non-anxious language learners' reactions to their own oral performance. The Modern Language Journal, 86(4), 562-570.

Gregersen, T., \& MacIntyre, P. D. (2014). Capitalizing on language learner's individuality. Bristol: Multilingual Matters.

Ho, Y. (2003). Audiotaped dialogue journals: An alternative form of speaking practice. ELT Journal, 7(3), $269-277$.

Hsu, H. C. (2016). Voice blogging and L2 speaking performance. Computer Assisted Language Learning, 13(2), 88-103.

Hürriyet. (2015). Turkey to offer free Internet to poor families. Retrieved from: http://www.hurriyetdailynews.com/turkey-to-offer-free-internet-to-poorfamilies - .aspx? pageID $=238 \& n I D=79448 \& N e w s C a t I D=341$

Ibarz, T., \& Webb, S. (2007). Listening to learners to investigate the viability of technology-driven ESOL pedagogy. Innovation in Language Learning and Teaching, 1(2), 208-226.

Inozu, J. (2011). Developing learner autonomy in the language class in Turkey: Voices from the classroom. Asia Pacific Education Review, 12, 523-531.

Inozu, J., Sahinkarakas, S., \& Yumru, H. (2010). The nature of language learning experiences beyond the classroom and its learning outcomes. US-China Foreign Language, 8(1), 14-22.

Kang, S. J. (2005). Dynamic emergence of situational willingness to communicate in a second language. System, 33, $277-292$.

Kağitçibaşi, C. (2007). Family, self, and human development across cultures: Theory and applications (2 $2^{\text {nd }}$ ed.). Mahwah: Lawrence Erlbaum.

Kırkgöz, Y. (2007). English language teaching in Turkey: Policy changes and their implementations. RELC Journal, 38, $216-228$.

Kirkgöz, Y. (2011). A blended learning study on implementing video recorded speaking tasks in task-based classroom instruction. TOJET, 10(4), 1-14.

Kızıldağ, A. (2009). Teaching English in Turkey: Dialogues with teachers about the challenges in public primary schools. International Electronic Journal of Elementary Education, 3, 180-201.

Lai, C., Zhu, W., \& Gong, G. (2015). Understanding the quality of out-of-class English learning. TESOL Quarterly, 49(2), 278-308.

Levine, G. S. (2003). Student and instructor beliefs and attitudes about target language use, first language use, and anxiety: Report of a questionnaire study. The Modern Language Journal, 87(3), 343-364.

Lin, H. (2014). Establishing an empirical link between computer-mediated communication (CMC) and SLA: A meta-analysis of the research. Language Learning \& Technology, 18(3), 120-147.

MacIntyre, P. D., Baker, S. C., Clément, R., \& Donovan, L. A. (2002). Sex and age effects on willingness to communicate, anxiety, perceived competence, and L2 motivation among junior high school French immersion students. Language Learning, 52, 537-564. 
MacIntyre, P., Burns, C., \& Jessome, A. (2011). Ambivalence about communicating in a second language: A qualitative study of french immersion students' willingness to communicate. The Modern Language Journal, 95(1), 81-96.

MacIntyre, P. D., Clément, R., Dörnyei, Z., \& Noels, K. A. (1998). Conceptualizing willingness to communicate in a L2: A situational model of L2 confidence and affiliation. The Modern Language Journal, 82(4), 545-562.

Milli Eğitim Bakanliği [Ministry of Education]. (2013). İlköğretim Kurumlari (İlkokullar Ve Ortaokullar) İngilizce Dersi Öğretim Programi [Elementary and intermediate school English language teaching program]. Ankara: T.C. Millî Eğitim Bakanliği. Retrieved from http://s2.morpakampus.com/userfiles/ image/haber_im/ingilizce_2-8.pdf.

Milli Eğitim Bakanlığı [Ministry of Education]. (2012). The Fatih project. Retrieved from: http://Fatihprojesi.meb.gov.tr/tr/english.php.

Moss, G., Jewitt, C., Levaãiç, R., Armstrong, V., Cardini, A., \& Castle, F. (2007). The interactive whiteboards, pedagogy and pupil performance evaluation: An evaluation of the schools whiteboard expansion (SWE) project: London challenge. Institute of Education, University of London. Research report, (816).

Nacak, M., Yağmurlu, B., Durgel, E., \& van de Vijver, F. (2011). Metropol ve Anadolu'da Ebeveynlik: Biliș ve Davranıșlarda Sehrin ve Eğitim Düzeyinin Rolü [The role of city and education on parenting beliefs and behaviors]. Türk Psikoloji Dergisi, 26, 85-104.

Sanprasert, N. (2009). The application of a course management system to enhance autonomy in learning English as a foreign language. System, 38, $109-123$.

Satar, H. M., \& Özdener, N. (2008). The effects of synchronous CMC on speaking proficiency and anxiety: Text versus voice chat. Modern Language Journal, 92, 595-613.

Selvi, A. F. (2011). World Englishes in the Turkish sociolinguistic context. World Englishes, 30(2), $182-199$.

Shenton, A., \& Pagett, L. (2007). From 'bored' to screen: The use of the interactive whiteboard for literacy in six primary classrooms in England. Literacy, 41(3), 129-136.

State Planning Organization (SPO). (2006). Information society strategy (2006-2010). Retrieved from: http://www.bilgitoplumu.gov.tr/Documents/5/ Documents/060700_InformationSocietyStrategypdf.

Sun, Y.-C. (2012). Examining the effectiveness of extensive speaking practice via voice blogs in a foreign language learning context. CALICO Journal, 29(3), 494-506.

Sundqvist, P. (2011). A possible path to progress: Out-of-school English language learners in Sweden. In P. Benson, \& H. Reinders (Eds.), Beyond the language classroom (pp. 106-118). Basingstoke: Palgrave MacMillan.

Tatar, T. (2005). Why keep Silent? The classroom participation experiences of non-native-English-speaking students. Language and Intercultural Communication, 5(3-4), 284-293.

TEPAV. (2013). Turkey national needs assessment of state school English language teaching. Ankara: TEPAV/British Council.

Tok, H. (2009). EFL Leaners' communication obstacles. Electronic journal of Social Science, 29, 84-100.

Turkish Statistical Institute [Türkiye İstatistik Kurumu]. (2013). Household use of information technologies, [Hanehalkı bilişim teknolojileri kullanım araștırması]. Turkish Statistical Institute News Bulletin [Turkiye İstatistik Kurumu Haber Bülteni], No: 13569 Accessed October, 2016.Retrieved from http:// tuik.gov.tr/PreHaberBultenleri.do?id=13569.

Uztosun, M. S. (2013). An interpretive study into elementary school English teachers' beliefs and practices in Turkey. Turkish Online Journal of Qualitative Inquiry, 4(1), 20-33.

Webb, S. (2006). Can ICT reduce social exclusion? The case of an adults' English language learning programme. British Educational Research Journal, 32(3), $481-507$.

Yashima, T., Zenuk-Nishide, L., \& Shimizu, K. (2004). The influence of attitudes and affect on willingness to communicate and second language communication. Language Learning, 54, 119-152. 